\title{
EDITORIAL
}

\section{The futurology of revenue management and pricing}

Journal of Revenue and Pricing Management (2007) 6, 251-252. doi:10.1057/palgrave.rpm.5160115

Imagine that you could predict whether house prices are about to crash. Alternatively, how a political party could choose policies guaranteeing electoral victory. On the other hand, whether a new set of criminal laws will reduce crime, or whether a new road will reduce traffic, or even whether your favourite pub will be overcrowded on the nights it shows live football. This is the world of futurology where science and art combine to predict the future. To a certain extent, revenue managers are futurologists who predict the future using the best of both science and art. As it is difficult to predict an exact future, this issue is devoted to plausible and multiple futures by asking a range of experts in revenue management and pricing to look into the future.

Some of the predictions and insights include:

- By 2020 revenue management technology is widely available off the shelf and advances in software engineering makes it ever easier to adapt it to the needs of specific client. Therefore, any company with enough funding can acquire any number of highly automated solutions. The mathematical algorithms in the optimisation black boxes are well known and already incorporated as standard features of most software packages. Therefore, those who have adopted revenue management and adapted to it well are among the survivors in our projected timeframe, while those who failed to do so are long gone.
- Watch out for the pizza delivery model as developed by www.easypizza.com

- The future is web analytics.

- The future depends on exchange rates rather than pricing models.

- Price has nothing to do with tourist flows, especially in the USA. It's all about perception and brand.

- Demand management is a logical expansion of traditional yield management. It raises the level of responsibility and activity of users from merely controlling demand at the bottom of the demand funnel to cost-effectively keeping the funnel full placing a more concerted effort on the marketing aspects of RM in an attempt to thwart the commoditisation that exists owing to price transparency.

- Revenue management should be called 'Displacement Optimisation' (DO) because we are really just determining what demand to accept and reject based on a displacement process.

- Companies can no longer afford to fail in their pricing decisions; all products and services must be priced right, all of the time.

- Much of the world's manufacturing is now conducted in emerging economies. Clearly, managing long and complex supply chains is an area ripe for revenue management.

- Cargo customers are looking to decrease their costs. Advanced Cargo RM systems can help customers meet that goal through automation and use of RM tools by intelligently and automatically extracting value from the customer only where there is market 
demand and offering alternatives for lower cost options.

- Revenue management will achieve significant gains over the next 5-10 years through greater consideration of the hybrid nature of the market and through use of technology to bring more data and analysis to bear on the problem and control at a finer level of granularity.

- The firm does not benefit from customers waiting nor do customers like waiting.

- Will customers understand the difference between 'made in Italy' and 'made in China' in the future?

- The future is the feedback loop.
- How much would you pay for cruise control?

- The customer is now the revenue manager, not the airline.

- Revenue managers of the future will be good car sales persons. So, therefore it looks dodgy.

- We have to think in terms of expected reimbursements from the payers and patients' ability-to-pay as opposed to willingness-topay to accurately model a hospital's revenues.

Ian Yeoman and Gina Morello Guest Editors 